\title{
COMUNICAÇÃO
}

\section{EFEITO IN VITRO DE COMPOSTOS DE PLANTAS SOBRE O FUNGO Colletotrichum gloeosporioides Penz. ISOLADO DO MARACUJAZEIRO}

\author{
In vitro effect of plant compounds on the fungus Colletotrichum gloeosporioides Penz. \\ isolated from passion fruit
}

\author{
André Costa da Silva ${ }^{1}$, Nilza de Lima Pereira Sales², Alisson Vinícius de Araújo ${ }^{3}$, Cecílio Frois Caldeira Júnior ${ }^{4}$
}

\begin{abstract}
RESUMO
Neste trabalho, objetivou-se avaliar o efeito de extratos e óleos essenciais de quatorze plantas medicinais e ou nativas, conhecidas popularmente no Norte de Minas Gerais, sobre a germinação de esporos e crescimento micelial do fungo Colletotrichum gloeosporioides. Foram utilizados no teste de inibição do crescimento micelial, os extratos aquosos de alecrim (Rosmarinus officinalis), erva baleeira (Cordia verbenacea), joá (Solanum sisymbriifolium), quebra-pedra (Phyllanthus corcovadensis), erva botão (Eclipta alba) e açafrão da índia (Curcuma longa) obtidos por meio do processo de infusão; óleo essencial de alecrim de vargem (Família Lamiaceae), alecrim pimenta (Lippia sidoides), alfavaca cravo (Ocimum gratissimum), lippia (Lippia citriodora), goiaba branca (Psidium guajava), capim santo (Cymbopogon citratus); óleo resina de copaíba (Copaifera langsdorffi); hidrolatos de alecrim de vargem, goiaba vermelha (Psidium guajava), lippia, capim santo, goiaba branca, alfavaca cravo; manipueira de (Manihot esculenta). Também foram testados esses mesmos hidrolatos e os óleos essenciais na germinação dos esporos do fungo. Todos os tratamentos foram realizados in vitro, cultivando-se o fungo em meio de cultura BDA acrescido de 100 $\mu \mathrm{L}$ dos compostos vegetais. No teste de inibição da germinação, todos os óleos essenciais impediram a germinação do fungo. No entanto, os hidrolatos não tiveram esse efeito. No teste de crescimento micelial, os óleos essenciais de todas as plantas inibiram completamente o crescimento do fungo, exceto o óleo da goiaba branca. Os extratos aquosos, a manipueira, o óleo resina e os hidrolatos, também não foram eficientes sobre o crescimento do patógeno. Esses resultados indicam o potencial antifúngico de alguns óleos essenciais de plantas medicinais.
\end{abstract}

Termos para indexação: Controle alternativo, antracnose, maracujá, plantas medicinais ou nativas.

\begin{abstract}
The objective of the work was to evaluate the effect of extracts and essential oils of fourteen medicinal and or native plants popularly known in the North of Minas Gerais, on the germination of spores and the mycelial growth of Colletotrichum gloeosporioides fungus. The following were used in the mycelial growth inhibition test: the watery extracts of rosemary (Rosmarinus officinalis), Cordia verbenacea, Solanum sisymbriifolium, Phyllanthus corcovadensis, Eclipta alba, and Curcuma longa obtained through the infusion process; essential oils of "alecrim de vargem" (Lamiaceae Family), Lippia sidoides, Ocimum gratissimum, Lippia citriodora, white guava (Psidium guajava), lemongrass (Cymbopogon citratus); copaíba oil resin (Copaifera langsdorffi) as well as hydrolates of "alecrim de vargem", red guava (Psidium guajava), Lippia citriodora, lemongrass, white guava, Ocimum gratissimum; and cassava manipueira (Manihot esculenta). The same hydrolates and essential oils were also tested on the germination of the fungus spores. All the treatments were carried out in vitro, cultivating the fungus in PDA supplemented with $100 \mu \mathrm{L}$ of the vegetal compounds. In the germination inhibition test, all the essential oils prevented the germination of the fungus. However, the hydrolates did not have this effect. In the mycelial growth test, the essential oils of all of the plants completely inhibited the fungus growth, except the white guava oil. The watery extracts, the cassava manipueira, the oil resin and hydrolates were also not efficient in preventing the growth of the pathogen. These results indicate the fungitoxic potential of some essential oils of medicinal plants.
\end{abstract}

Index terms: Alternative control, anthracnose, passion fruit, medicinal or native plants.

(Recebido em 9 de agosto de 2007 e aprovado em 15 de setembro de 2008)

\footnotetext{
${ }^{1}$ Engenheiro Agrônomo, Doutorando em Fitopatologia/Universidade Federal de Lavras /UFLA - Cx. P. 3037 - 37.200-000 - Lavras/MG andrec_agro@yahoo.com.br

²Engenheira Florestal, D.Sc., Professora de Fitopatologia/Universidade Federal de Minas Gerais/UFMG - Cx. P. 135 - $39.404-006$ - Montes Claros/MG nsales@nca.ufmg.br

${ }^{3}$ Engenheiro Agrônomo, Mestrando em Agroecologia/Universidade Federal de Minas Gerais/UFMG - Cx. P. 135 - $39.404-006$ - Montes Claros/MG viniciusnca@yahoo.com.br

${ }^{4}$ Engenheiro Agrônomo, Doutorando em Fisiologia vegetal/Universidade de São Paulo/ESALQ - Cx. P. 9 - 13.418-900 - Piracicaba/SP agrosuacui@yahoo.com.br
} 
A cultura do maracujazeiro é muito importante para a região Norte do estado de Minas Gerais, por ser responsável pela agregação de renda para diversos agricultores familiares, que, em contraste com a atividade agrícola altamente tecnificada, encontra-se numa outra realidade, na qual, além do extrativismo de frutos do cerrado, como o pequi, o umbu, araticum, dentre outros, também possuem pomares rudimentares em suas propriedades, tais como de maracujá que é comercializado em feiras, supermercados, CEANORTE e para pequenas Agroindústrias. Entretanto, a produtividade desses pomares é baixa e o produto oferecido é de qualidade inferior, o que recebe cotações menores no comércio (Lopes, 2003).

Um dos principais entraves ao desenvolvimento dessa cultura junto aos produtores é a ocorrência de doenças, entre elas, a antracnose, cujo agente causal é o fungo Colletrotrichum gloeosporioides Penz. Trata-se de uma doença promotora de grandes prejuízos, principalmente, em época quente e chuvosa, característica do verão norte-mineiro causando intensa desfolha, seca de ramos e apodrecimento de frutos. Pode também ocorrer na fase de pós-colheita (Picanço \& Bruckner, 2001). Por ser uma doença que reduz a quantidade e a qualidade dos frutos, precisa-se da adoção de medidas de manejo.

As medidas de controle, normalmente usadas pelos grandes produtores, incluem o uso de produtos químicos o que onera grandemente o custo de produção e torna inviável a adoção dessa prática pelos agricultores orgânicos e familiares. Além disso, a sociedade busca hoje, formas de vida mais saudável e com esse propósito, a comunidade científica tem buscado maneiras alternativas de controle de pragas e doenças. Com o conhecimento atual sobre os impactos ambientais, problemas relacionados à intoxicação do homem, resistência de microrganismo, as pesquisas têm buscado produtos alternativos de baixo custo e inócuos ao homem e ao ambiente (Stadnik \& Rivera, 2001).

A identificação de novos compostos químicos a partir de plantas nativas e/ou medicinais possibilita a obtenção de algumas substâncias capazes de controlar ou inibir o desenvolvimento dos fitopatógenos e, segundo Stadnik \& Talamini (2004), os produtos naturais de plantas podem apresentar três atividades principais: antimicrobiana, agindo direto sobre o patógeno; indutores de resistência, ativando os mecanismo de defesa da planta através de moléculas bioativas e também como bioestimulantes do crescimento da planta.

O uso de plantas no tratamento de doenças humanas e de animais é bem conhecido de longas datas, porém, o seu uso no tratamento das doenças de plantas e controle de pragas é mais recente. Em alguns trabalhos têm-se estudado o efeito de extratos e óleos essenciais de plantas sobre fungos fitopatogênicos (Pandey \& Dubey, 1992; Coutinho et al., 1999; Ribeiro et al., 1999; Marques et al., 2002; Salgado et al., 2003; Bastos \& Albuquerque, 2004; Amaral, 2005; Pereira, 2006; Medice et al., 2007; SILVA et al., 2008) entre outros.

Assim, nesta pesquisa, objetivou-se avaliar in vitro, o efeito dos extratos e dos óleos essenciais de quatorze plantas medicinais e/ou nativas conhecidas popularmente na Região Norte de Minas Gerais, sobre a germinação dos esporos e sobre o crescimento micelial do fungo.

Os experimentos para avaliar o efeito antifúngico dos extratos e dos óleos essenciais de plantas, foram realizados nos Laboratórios de Fitopatologia e de Plantas Medicinais do Instituto de Ciências Agrárias (ICA) da UFMG, Montes Claros - MG, no período de Junho a Novembro de 2006.

$\mathrm{O}$ fungo foi obtido a partir do seu isolamento de folhas de maracujazeiro com sintomas de antracnose, do pomar do ICA. Foi cultivado em meio BDA (batata, dextrose, agar- $200 \mathrm{~g}, 20 \mathrm{~g}, 20 \mathrm{~g}$ ) por 15 dias, sob fotoperíodo de $12 \mathrm{~h}$, $25^{\circ} \mathrm{C}$ em estufa incubadora.

Obteve-se uma cultura monospórica a partir do isolado inicial. Para isso, parte da colônia do fungo foi adicionada em um tubo de ensaio, contendo $10 \mathrm{~mL}$ de água destilada esterilizada, agitando-se por alguns minutos para promover a liberação dos esporos. Diluiu-se quatro vezes esta suspensão inicial com o objetivo de alcançar um menor número de esporos por mililitro de água. A partir da última diluição coletou-se $1 \mathrm{~mL}$ da suspensão e semeou em placas de Petri com o meio ágar-água. Todo o procedimento foi realizado sob condições assépticas, em câmara de fluxo laminar. Foram realizadas quatro repetições. Acondicionaram-se as placas em estufa incubadora, sob o regime de $9 \mathrm{~h}$ de luz e a $25^{\circ} \mathrm{C}$. Após esse período, a superfície de cada placa foi observada ao microscópio óptico para constatar a germinação dos esporos. O esporo do fungo que se encontrava com o tubo germinativo desenvolvido e, separado no campo de visão da objetiva do microscópio foi cortado do meio de cultura com o auxílio de um aparelho desenvolvido pela EMBRAPA Milho e Sorgo e transferido para um tubo de ensaio contendo BDA. Os tubos foram acondicionados em estufa incubadora, a $25^{\circ} \mathrm{C}$, sob fotoperíodo de $12 \mathrm{~h}$ luz até o crescimento das colônias monospóricas em 15 dias. Posteriormente, essas colônias foram repicadas para novas placas de Petri com BDA, obtendo-se, assim, a cultura de trabalho.

Os extratos aquosos foram obtidos a partir do processo de infusão de $200 \mathrm{~g}$ de folhas das plantas-teste, 
colhidas na parte da manhã, em 1 L de água destilada com temperatura em torno de $100^{\circ} \mathrm{C}$. Sob condições assépticas, em câmara de fluxo laminar, os extratos foram filtrados, inicialmente, em gaze e, posteriormente, em filtros tipo Millipore, para a esterilização.

Os óleos essenciais foram extraídos por hidrodestilação, usando o aparelho de Clevenger modificado. A parte aérea das plantas foi fragmentada e obteve-se a massa de $150 \mathrm{~g}$ que foi colocada em balão de vidro cobrindo-se com água destilada até atingir no máximo 2/ 3 do balão. O processo de extração foi conduzido por três horas, sendo que, ao final, o óleo foi separado da água por separação líquido-líquido e a fase aquosa foi utilizada como hidrolato.

A atividade antifúngica dos óleos essenciais e dos hidrolatos foi avaliada microscopicamente por meio da inibição da germinação dos esporos. Testaram-se os óleos essenciais e hidrolatos de alecrim de vargem (Família Lamiaceae), alfavaca cravo (Ocimum gratissimum L.), lippia (Lippia citriodora Kunth.), goiaba branca e goiaba vermelha (Psidium guajava L.), capim santo (Cymbopogon citratus Stapf.) e alecrim pimenta (Lippia sidoides Cham.) testando apenas seu óleo essencial.

Na câmara de fluxo laminar espalhou-se $100 \mu \mathrm{L}$ do óleo essencial ou do hidrolato na superfície das placas de Petri de $9 \mathrm{~cm}$ contendo $15 \mathrm{~mL}$ de Ágar-Água, com o auxílio de uma espátula de metal flambada. Logo em seguida, adicionou-se $500 \mu \mathrm{L}$ da suspensão de esporos na concentração de $7 \times 10^{4}$ esporos $/ \mathrm{mL}$. As placas foram incubadas em estufa incubadora, sob o regime de $9 \mathrm{~h}$ de luz a $25^{\circ} \mathrm{C}$. $\mathrm{O}$ ensaio foi conduzido em delineamento inteiramente casualizado com catorze tratamentos e quatro repetições. As placas foram divididas em quadrantes e, cada parte, consistiu numa repetição. A testemunha constituiu-se da suspensão de esporos mais água destilada estéril, sobre o meio de cultura. A avaliação do ensaio foi realizada $9 \mathrm{~h}$ após o início da incubação. Contou-se o número de esporos totais e germinados, no campo de visão da objetiva de 10X do microscópio óptico, em três pontos distintos de cada quadrante. Calculou-se a porcentagem de germinação dos esporos em cada repetição.

Procedeu-se a uma nova incubação das placas de Petri por mais sete dias após a avaliação, confirmando o desenvolvimento ou não de colônias do fungo na placa.

Os dados obtidos foram submetidos à análise de variância, sendo as médias comparadas pelo teste de Tukey $(\mathrm{P}<0,05)$ de probabilidade.

Para avaliação do efeito in vitro dos compostos de plantas sobre o crescimento micelial de $C$. gloeosporioides foram utilizados: extrato aquoso de alecrim (Rosmarinus officinalis L.), erva baleeira (Cordia verbeacea DC.), joá (Solanum sisymbriifolium Lam.), quebra-pedra (Phyllanthus corcovadensis Mull.Arg.), erva botão (Eclipta Alba Hassk.) e açafrão da índia (Curcuma longa L.); óleo essencial de alecrim de vargem (Família Lamiaceae); óleo resina de copaíba (Copaifera langsdorffi Desf.) e a manipueira filtrada de Manihot esculenta Crantz.. Para isso, $100 \mu \mathrm{L}$ dos compostos foram espalhados sobre $15 \mathrm{~mL}$ do meio BDA em placas de Petri de $9 \mathrm{~cm}$ de diâmetro, da mesma maneira que no ensaio de germinação de esporos. Cada placa foi introduzida, no centro, com um disco de 5 mm de diâmetro, contendo micélios da cultura monospórica, crescida há 7 dias em BDA. As placas também foram acondicionadas em estufa incubadora, a $25^{\circ} \mathrm{C}$ sob fotoperíodo de $12 \mathrm{~h}$. O ensaio foi montado em delineamento inteiramente casualizado com 10 tratamentos e três repetições. A testemunha consistiu de $100 \mu \mathrm{L}$ de água destilada estéril espalhada na superfície do meio BDA mais o disco do fungo. As avaliações foram realizadas por meio de medições diárias do diâmetro das colônias (média das duas medidas diametricamente opostas), iniciando-se $48 \mathrm{~h}$ após a montagem do ensaio e sempre no mesmo horário. As laterais das placas foram vedadas com filme plástico para evitar possíveis evaporações dos compostos. A avaliação foi realizada até o nono dia de incubação.

Em outra parte do experimento, avaliou-se o efeito in vitro de hidrolatos, óleos essenciais e manipueira autoclavada, sobre o crescimento micelial de $C$. gloeosporioides. Testou-se, neste ensaio, o efeito dos óleos essenciais de alecrim pimenta (Lippia sidoides), alfavaca cravo (Ocimum gratissimum), lippia (Lippia citriodora), goiaba branca (Psidium guajava), capim santo (Cymbopogon citratus ) e os seus hidrolatos; hidrolatos de alecrim de vargem (Família Lamiaceae) e goiaba vermelha (Psidium guayava); e manipueira autoclavada. $\mathrm{O}$ ensaio foi montado e conduzido como no ensaio anterior.

Os testes de crescimento micelial foram conduzidos em um esquema de parcelas subdivididas, tendo como fator principal o tempo e o fator secundário o tratamento. $\mathrm{O}$ efeito da interação tempo e tratamento foi significativo, procedendo-se com isso a análide de regressão para os dados, a um nível de significancia de $5 \%$.

Os hidrolatos obtidos de goiaba vermelha (Pisidium guajava); lippia (Lippia citriodora); capim santo (Cymbopogon citratus); goiaba branca (Pisidium guajava); alfavaca cravo (Ocimum gratissimum) e alecrim de vargem não afetaram a germinação dos esporos de $C$. gloeosporioides. Já os óleos essenciais obtidos dessas mesmas plantas e o óleo essencial de alecrim pimenta (Lippia sidoides) inibiram em $100 \%$ a germinação do fungo (tabela 1). 
Tabela 1 - Efeito de compostos de plantas sobre a germinação de esporos do fungo C. gloeosporioides.

\begin{tabular}{lc}
\hline \multicolumn{1}{c}{ Tratamentos } & $\begin{array}{c}\text { Esporos } \\
\text { germinados (\%) }\end{array}$ \\
\hline Hidrolato de Psidium guayava & $91 \mathrm{a}$ \\
Água estéril & $89 \mathrm{a}$ \\
Hidrolato de Cymbopogon citratus & $88 \mathrm{a}$ \\
Hidrolato de alecrim de vargem & $86 \mathrm{a}$ \\
Hidrolato de Lippia citriodora & $85 \mathrm{a}$ \\
Hidrolato de Psidium guajava & $83 \mathrm{a}$ \\
Hidrolato de Ocimum Gratissimum & $81 \mathrm{a}$ \\
Óleo essencial de Lippia sidoides & $0 \mathrm{~b}$ \\
Óleo essencial de Ocimum gratissimum & $0 \mathrm{~b}$ \\
Óleo essencial de Lippia citriodora & $0 \mathrm{~b}$ \\
Óleo essencial de Psidium guajava & $0 \mathrm{~b}$ \\
Óleo essencial de Psidium guayava & $0 \mathrm{~b}$ \\
Óleo essencial de Cymbopogon citratus & $0 \mathrm{~b}$ \\
Óleo essencial de alecrim de vargem & $0 \mathrm{~b}$ \\
\hline
\end{tabular}

Médias seguidas pelas mesmas letras minúsculas na coluna não diferem significativamente entre si pelo teste Tukey a $5 \%$ de probabilidade.

Observa-se, entretanto, que o hidrolato e o óleo essencial obtidos da mesma planta tiveram efeitos diferentes, isso pode ser decorrente da baixa concentração do(s) principio(s) ativo(s) nos hidrolatos em relação à concentração dos mesmos no óleo essencial, ou à falta de algum(s) princípio(s) ativo(s) que não seja solúvel em água. Após sete dias, verificou-se que, não ocorreu a germinação de esporos e, consequentemente, o crescimento micelial do fungo, nos tratamentos com os óleos essenciais.

Alves et al. (2002), relataram à eficiência dos óleos essenciais das plantas Cymbopogon citratus, C. nardus (L.) Rendle. e Eucalyptus citriodora Hook. no controle in vitro, da germinação de conídios e do crescimento micelial de Colletotrichum musae. Os óleos essenciais de Cymbopogon citratus inibiram completamente a germinação de esporos e o crescimento micelial do fungo Dydimella bryoniae, causador de danos às folhas e frutos de melão (Fiori et al., 2000).

Segundo Carriconde et al. (1996), o óleo essencial do $C$. citratus tem como propriedades terapêuticas ação antifúngica e antibacteriana, e que o principal componente do óleo essencial do $C$. citratus é o citral. Com isso, percebise a eficácia do óleo essencial $C$. citratus em efeito in vitro sobre importantes patógenos de plantas, como no caso do C. gloeosporioides, em que obteve $100 \%$ de inibição na sua germinação.
No teste de crescimento micelial, pode-se perceber que o óleo essencial do alecrim de vargem inibiu completamente o crescimento micelial do fungo, em todos os dias avaliados. Os demais tratamentos não tiveram efeito sobre o crescimento do fungo (Figura 1).

O fato dos tratamentos com óleo essencial terem efeito sobre os esporos e micélio do fungo, ao contrário dos extratos aquosos, pode ser explicado, segundo Silva (2006), pelas elevadas concentrações dos princípios ativos nos óleos em relação aos extratos. No entanto, pode ter ocorrido também que o processo de infusão não ter sido eficiente na extração dos princípios ativos fungitóxicos das plantas ou ocorrido perda de algum(s) princípio(s).

Segundo Fewell \& Roddick (1993), o joá (Solanum sisymbriifolium), planta herbácea encontrada no Cerrado, e pertencente à família das solanaceae, produz uma toxina conhecida por solanina, mais evidente nas sementes dos frutos verdes. Alguns pesquisadores já comprovaram a eficácia fungicida dessa substância no controle de alguns fungos fitopatogênicos, diferenciando-se assim, dos resultados obtidos, que pode ter sido decorrente do modo de extração que foi diferente da metodologia de extração (extrato aquoso) e o material usado (folhas), que não foi suficiente para a obtenção do princípio ativo.

Sobral et al. (2006), testando o óleo de andiroba e copaíba sobre o crescimento micelial do fungo Scytalidium lignicola nas concentrações de 1; 1,5 e 2,0\% observaram que, o óleo de andiroba não inibiu o crescimento micelial do patógeno, enquanto que o óleo de copaíba na concentração de $1,5 \%$ inibiu o crescimento em $34 \%$. Amorim et al. (2004), avaliando a atividade fungitóxica dos extratos foliares hexânico e metanólico da Copaifera langsdorffi, sobre os fungos Colletotrichum gloeosporioides e Bipolaris sorokiniana, observou-se que o extrato de hexânico foi eficaz para ambos os fitopatógenos, apresentando uma redução de $18 \%$ para o C. gloeosporioides, diferenciando do assim do atual experimento que utilizou o óleo resina e não o extrato foliar como citado acima.

A utilização de plantas no controle de patógenos apresenta alguns entraves, pois, a composição química e a quantidade são variáveis, dependendo da idade da planta, do tipo de tecido, do tipo de solo e do seu hábitat. Isso explica, em parte, a discrepância encontrada entre as pesquisas realizadas em diferentes locais com a mesma metodologia e a mesma espécie de planta (Silva, 2006). 

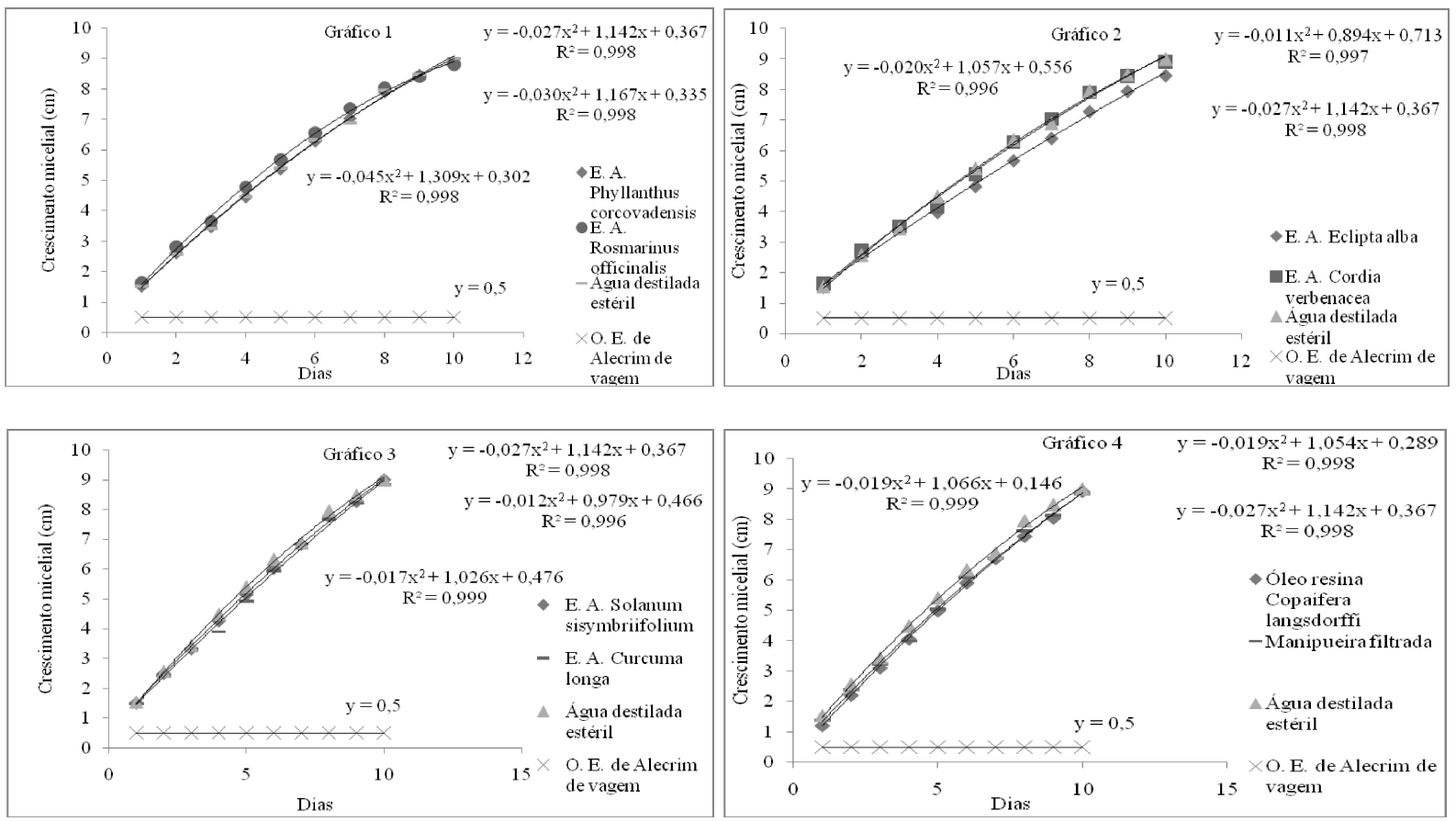

Figura 1 - Efeitos de Extratos aquosos (E.A.) óleo essencial (O.E.), óleo resina e manipueira sobre o crescimento micelial de C. gloeosporioides em meio BDA.

No outro experimento testando hidrolatos, óleos essenciais e manipueira autoclavada observou-se que os hidrolatos testados, apenas o de alfavaca cravo (Ocimum gratissimum), teve uma pequena inibição sobre o crescimento do fungo (Fig. 2, gráfico 6). Os óleos essenciais obtiveram um resultado positivo sobre o crescimento do C. gloeosporioides, sendo que o óleo de Lippia citriodora, Lippia sidoides e Ocimum gratissimum inibiram em 100\% o seu crescimento micelial (Figura 2). O óleo de Cymbopogon citratus, apesar de ter promovido um crescimento mínimo a partir do quinto dia não diferiu dos demais, promovendo um ótimo efeito sobre o crescimento do patógeno (Fig. 2, gráfico 3). Fazendo uma comparação do efeito do óleo essencial e do seu hidrolato, percebe-se um efeito inibitório do óleo o que não acontece com o seu hidrolato.

O óleo de goiaba branca, apesar de não ter tido efeito no crescimento do fungo (Fig. 2, gráfico 4), inibiu completamente a germinação dos esporos, conforme experimento 1. Tal fato pode ser decorrente da sensibilidade dos esporos a algum(s) composto(s) químico(s) que a goiaba possua e, que o micélio não seja sensível, porém, novos trabalhos deverão esclarecer melhor tal ação.
O crescimento micelial dos fungos Fusarium solani, Sclerotinia sclerotiorum e Rhizoctonia solani foi totalmente inibido com o tratamento do óleo essencial de Cymbopogon citratus (Valarini et al., 1995) e, segundo Rozwalka et al. (2008), o óleo essencial de Cymbopogon citratus inibiu totalmente o fungo Colletotrichum gloeosporioides isolado de goiaba.

Segundo Bertini et al. (2005), o principal constituinte da Lippia sidoides é o timol que tem uma forte atividade contra bactérias e fungos e que a eficácia dessa planta foi demonstrada pelo óleo essencial das folhas, que contém timol e carvacrol como principais constituintes.

Lemos et al. (1990) verificou que o óleo essencial de Lippia sidoides exibiu grande atividade contra todos os microrganismos testados, como Saccharomyces cerevisiae, Aspergillus flavus e Cryptococcus neoformans.

Segundo Pessoa et al. (1996), o óleo essencial de Lippia sidoides (alecrim-pimenta) a 10\%, em teste in vitro, inibiu o crescimento micelial de Macrophomina phaseolina, Fusarium oxysporum, Colletotrichum gloeosporioides e Rhizopus sp. 
SILVA, A. C. da et al.
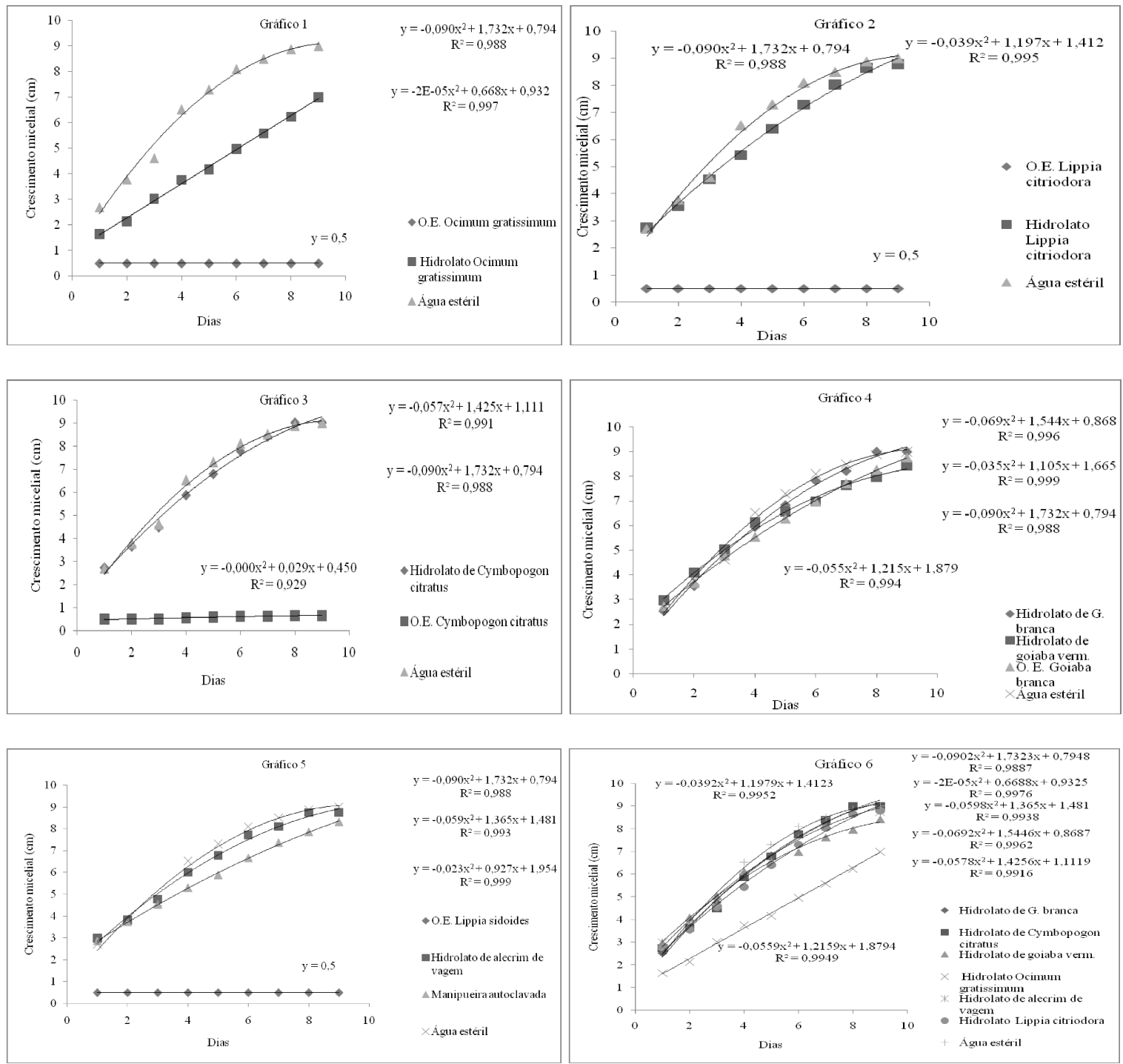

Figura 2 - Efeitos dos Hidrolatos, óleos essenciais (O.E.) e manipueira sobre o crescimento micelial de $C$. gloeosporioidesdoses em meio BDA.

Stangarlin et al. (1999) detectaram, por meio de cromatografia delgada, a presença de compostos fungitóxicos em óleo derivados de plantas medicinais, inibindo o desenvolvimento de Colletotrichum graminicola. Observaram também a presença de duas frações fungitóxicas bem definidas nos extratos de erva cidreira e uma na alfavaca.

No tratamento com a manipueira autoclavada, observou-se que o mesmo não teve efeito no crescimento micelial do fungo, isso pode ter ocorrido pelo fato da substância tóxica e volátil linamarina ter sido evaporada durante o processo de autoclavagem, assim como pode ter havido degradação de compostos fungitóxicos.

Bonaldo et al. (2004), trabalhando com extratos aquosos autoclavados e não autoclavados concluiu que o tratamento térmico promove modificações no extrato.

Com base nos experimentos, conclui-se que os óleos essenciais de goiaba vermelha (Pisidium guajava), lippia (Lippia citriodora), capim santo (Cymbopogon citratus), goiaba branca (Pisidium guajava), alfavaca cravo (Ocimum gratissimum), alecrim pimenta (Lippia sidoides) e alecrim de vargem inibiram em $100 \%$ a germinação do fungo. Os 
óleos essenciais do alecrim de vargem, lippia (Lippia citriodora), alecrim pimenta (Lippia sidoides) e alfavaca cravo (Ocimum gratissimum) inibiram completamente o crescimento micelial do Colletotrichum gloeosporioides e que os extratos aquosos obtidos por meio de infusão, a manipueira filtrada e a autoclavada e os hidrolatos não foram eficientes no crescimento micelial e/ou germinação do fungo.

O uso de plantas medicinais no controle do $C$. gloeosporioides do maracujazeiro pode ser uma alternativa eficiente e ecológica, apresentando um grande potencial de aplicação em um programa de manejo integrado no controle da antracnose do maracujazeiro, portanto, ensaios precisam ser efetuados em campo para comprovar tal efeito.

\section{AGRADECIMENTOS}

Ao CNPq, pelo financiamento da pesquisa realizada.

\section{REFERÊNCIAS BIBLIOGRÁFICAS}

ALVES, E.S.S.; SANTOS, M.P.; VENTURA, J.A.; FERNANDES, P.M.B. Eficiência de óleos essenciais no controle in vitro da germinação de conídios e do crescimento micelial de Colletotrichum musae. Fitopatologia Brasileira, Brasília, v.27, p.75, 2002. Resumo. Disponível em: <http://www.seagri.ba.gov.bri 'Maracuja.htm'>. Acesso em: 22 nov. 2006.

AMARAL, D.R. Indução de resistência em cafeeiro contra Cercospora coffeicola por eliciadores abióticos e extratos vegetais. 2005. Dissertação (Mestrado Fitopatologia)Universidade Federal de Lavras, Lavras, 2005.

AMORIM, A.C.L.; CARDOSO, M.G.; PINTO, J.E.B.P.; SOUZA, P.E. de; DELÚ FILHO, N. Fungitoxic activity avaliation of hexane and methanol extracts of copaíba plant leaves Copaifera langsdorffi Desfon. Ciência e Agrotecnologia, Lavras, v.28, n.2, p.314-322, mar./abr. 2004.

BASTOS, C.N.; ALBUQUERQUE, S.B. Efeito do óleo de Piper aduncum no controle em pós-colheita de Colletotrichum musae em banana. Fitopatologia Brasileira, Brasília, v.29, n.5, p.121-127, set./out. 2004.

BERTINI, L.M.; PEREIRA, A.F.; OLIVEIRA, C.L.L.; MENEZES, E.A.; MORAIS, S.M.; CUNHA, F.A.; CAVALCANTI, E.S.B. Perfil de sensibilidade de bactérias frente a óleos essenciais de algumas plantas no Nordeste do Brasil. Informa, San Salvador, v.17, n.3/4, p.21-27, 2005.

BONALDO, S.M.; SCHWAN-ESTRADA, K.R.F.; STANGARLIN, J.R.; TESSMANN, D.J.; SCAPIM, C.A.
Fungitoxicidade, atividade elicitora de fitoalexinas e proteção de pepino contra Colletotrichum lagenarium, pelo extrato aquoso de Eucalyptus citriodora.

Fitopatologia Brasileira, Brasília, v.29, n.2, p.121127, mar./abr. 2004.

CARRICONDE, C.; MORES, D.; FRITSCHEN, M. von; CARDOZO JUNIOR, E.L. Plantas medicinais e alimentícias. Olinda: Centro Nordestino de Medicina Popular; UFRPE, 1996. v.1.

COUTINHHO, W.M.; ARAÚJO, E.; MAGALHÃES, F.H.L. Efeitos de extratos de plantas anacardiáceas e dos fungicidas químicos benomyl e captan sobre a micoflora e qualidade fisiológica de sementes de feijoeiro (Phaseolus vulgaris L.). Ciência de Agrotecnologia, Lavras, v.23, n.3, p.560-568, jul./set. 1999.

FEWELL, A.M.; RODDICK, J. Interactive antifungal activity of glycoalkaloids á-solanine e á-chaconine. Phytochemistry, Oxford, v.33, n.2, p.323-328, 1993.

FIORI, A.C.G.; SCHWAN-ESTRATA, K.R.F.; STANGARLIN, J.R.; VIDA, J.B.; SCAPIM, C.A.; CRUZ, M.E.S.; PASCHOLATI, S.F. Antifungal activity of leaf extracts and essential oils of some medicinal plants against Didymella bryoniae. Journal of Phytopathology, Saint Paul, v.148, p.483-487, 2000.

LEMOS, T.L.G.; MATOS, F.J.A.; ALENCAR, J.W.; CRAVERO, A.A.; CLARK, A.M.; McCHESNEY, J.D. Antimicrobial activity of essential oils of brasilian plants. Phytoterapy Research, Chichester, v.4, n.2, p.82-84, 1990.

LOPES, P.S.N. Diagnósticos de pequenos fruticultores na comunidade rural de abóboras, município de Montes Claros - MG. Montes Claros: NCA/UFMG, 2003. 26p. Projeto de extensão.

MARQUES, M.C.S.; CARDOSO, M. das G.; SOUZA, P.E.; GAVILANES, M.L.; SOUZA, J.A.; PEREIRA, N.E.; NEGRÃO, I.O. Efeito fungitóxico dos extratos de Caryocar brasiliense Camb. sobre os fungos Botrytis cinerea, Colletotrichum truncatum e Fusarium oxysporum. Ciência e Agrotecnologia, Lavras, v.26, p.1410-1419, dez. 2002. Edição especial.

MEDICE, R.; ALVES, E.; ASSIS, R.T.; MAGNNO JUNIOR, R.G.; LOPES, E.A.G.L. Óleos essenciais no controle da ferrugem asiática da soja Phakopsora pachyrhizi Syd. \& P. Syd. Ciência e Agrotecnologia, Lavras, v.31, n.1, p.83-90, jan./fev. 2007. 
PANDEY, V.N.; DUBEY, N.K. Effect of essential oils from some higher plants against fungi causing damping-off disease. Biology Plantarum, Copenhagen, v.34, n.1/2, p.143-147, 1992.

PEREIRA, R.B. Extrato de casca de café e óleo de tomilho no controle de Cercospora coffeicola Berk \& Cooke em cafeeiro. 2006. Dissertação (Mestrado em Fitopatologia)-Universidade Federal de Lavras, Lavras, 2006.

PESSOA, M.N.G.; OLIVEIRA, J.C.M.; INNECCO, R. Efeito da tintura de alecrim-pimenta contra fungos fitopatogênicos in vitro. In: CONGRESSO BRASILEIRO DE FITOPATOlOGIA, 29., 1996, Campo Grande. Anais... Campo Grande, 1996. v.1.

PICANÇO, M.C.; BRUCKNER, C.H. Maracujá: tecnologia de produção, pós-colheita, agroindústria, mercado. Porto Alegre: Cinco Continentes, 2001. 472p.

RIBEIRO, L.F.; BEDENDO, I.P. Efeito inibitório de extratos vegetais sobre Colletotrichum gloeosporioides: agente causal da podridão de frutos de mamoeiro. Scientia Agricola, Piracicaba, v.56, n.4, p.21-27, 1999.

ROZWALKA, L.C.; LIMA, M.L.R.Z.C.; MIO, L.L.M. Extratos, decoctos e óleos essenciais de plantas medicinais e aromáticas na inibição de Glomerella cingulata e Colletotrichum gloeosporioides de frutos de goiaba. Ciência Rural, Santa Maria, v.38, n.2, p.31-36, 2008.

SALGADO, A.P.S.; CARDOSO, M. das G.; SOUZA, P.E.; SOUZA, J.A.; ABREU, C.M.P.; PINTO, J.E.B.P. Avalilação da atividade fungitóxica de óleos essenciais de folhas de Eucalyptus sobre Fusarium oxysporum, Botrytis cinerea e Bipoloris sorokiniana. Ciência e Agrotecnologia, Lavras, v.27, n.2, p.249-254, mar./abr. 2003.

SILVA, G.S. Substâncias naturais: uma alternativa para o controle de doenças. Fitopatologia Brasileira, Brasília, v.31, p.9, ago. 2006. Palestra 5.

SILVA, P. A.; OLIVEIRA, D. F.; PRADO, N. R. T do; CARVALHO, D. A. de; CARVALHO, G. A. de. Evaluation of the antifungal activity by plant extracts against Colletotrichum gloeosporioides Penz. Ciência e Agrotecnologia, Lavras, v.32, n.2, p.420-428, mar./abr., 2008.

SOBRAL, M.F.; CARNAUBA, J.P.; SILVA, J.C.; AMORIM, E.P.R. Efeito in vitro de óleos de andiroba e copaíba no crescimento micelial de Scytalidium lignicola.

Fitopatologia Brasileira, Brasília, v.31, p.12, 2006. Resumo.

STADNIK, M.J.; RIVERA, M.C. Ódios. Jaguariúna: Embrapa Meio Ambiente, 2001. 484p.

STADNIK, M.J.; TALAMINI, V. Extratos vegetais e de algas no controle de doenças de plantas. In: Manejo ecológico de doenças de plantas. Florianópolis: CCA/UFSC, 2004. p.45-62.

STANGARLIN, J.R.; SCHWAN-ESTRADA, K.R.F.; CRUZ, M.E.S.; NOZAKI, M.H. Plantas medicinais e controle alternativo de fitopatógenos. Biotecnologia Ciência \& Desenvolvimento, Brasília, v.11, p.16-21, 1999.

VALARINI, J.P.; FRIGHETTO, R.T.S.; SPADOTTO, C.A. Potencial da erva medicinal (Cymbopogon citratus) no controle de fitopatógeno do feijoeiro e plantas daninhas em área irrigada. Fitopatologia Brasileira, Brasília, v.20, p.121-127, 1995. Suplemento. 